\title{
Influência do manejo químico no capim amargoso em cultivo de soja
}

\author{
Pablo Rafael SCHNEIDER ${ }^{1}$, Lara Caroline Alves de OLIVEIRA ${ }^{1}$, Oscar Mitsuo YAMASHITA ${ }^{1 *}$ \\ Rubens Vieira MAIA ${ }^{1}$, Jean Correia de OLIVEIRA ${ }^{1}$, Marco Antonio Camilo de CARVALHO ${ }^{1}$
}

${ }^{1}$ Universidade do Estado de Mato Grosso, Alta Floresta, MT, Brasil.

(ORCID: 0000-0002-3651-4623; 0000-0001-9061-0408; *; 0000-0001-9610-2789; 0000-0001-9610-2789; 0000-0002-4971-2530; 0000-0003-4966-1013)

*E-mail: yama@unemat.br (ORCID: 0000-0001-6715-626X)

Recebido em: 27/02/2019; Aceito em: 24/06/2019; Publicado em: 04/02/2020.

\begin{abstract}
RESUMO: A soja é uma cultura de elevado potencial produtivo, entretanto sua produção é limitada pelas plantas daninhas, devido a competição por fatores abióticos, além de produzir substancias alelopáticas capazes de interferir na qualidade e produtividade da cultura. Objetivou-se avaliar a eficiência do herbicida glyphosate, isolado ou em mistura com haloxifop-p-metílico, no controle do capim-amargoso (Digitaria insularis). O trabalho foi desenvolvido em área experimental com a cultura da soja e desenvolvimento espontâneo de plantas daninhas. Os tratamentos foram: dose recomendada de glyphosate $\left(720 \mathrm{~g} \mathrm{ha}^{-1}\right.$ e.a.); dose recomendada de haloxyfop (60 g ha ${ }^{-1}$ i.a.); meia dose de glyphosate + meia dose de haloxyfop (360 $\mathrm{g} \mathrm{ha}^{-1}$ e.a. $+30 \mathrm{~g} \mathrm{ha}^{-1}$ i.a., respectivamente); dose recomendada de glyphosate + haloxyfop; meia dose de glyphosate + dose recomendada de haloxyfop; dose recomendada de glyphosate + meia dose de haloxyfop; testemunha sem a presença de plantas daninhas e com presença de daninhas. Foram avaliados os componentes produtivos da soja, fitotoxicidade do herbicida na cultura e na espécie invasora, e a massa vegetal da planta daninha. Os tratamentos com haloxyfop isolado ou em mistura com glyphosate promovem amarelecimento evoluindo para necrose do capim-amargoso, entretanto, em aplicação de glyphosate isoladamente, este apresentou pouco ou nenhum efeito sobre as plantas daninhas, indicando possível tolerância do biótipo do capim amargoso ao glyphosate. A produtividade da soja apresenta decréscimo de até $3.059 \mathrm{~kg} \mathrm{ha}^{-1}(90,10 \%)$ quando comparado com áreas onde houve aplicação. A população de plantas de soja por metro linear é reduzida significativamente quando não há o controle químico das plantas daninhas.
\end{abstract}

Palavras-chave: Digitaria insularis; fitointoxicação; herbicida.

\section{Influence of chemical management in the bitter capim in soybean cultivation}

\begin{abstract}
Soybean is a crop with high productive potential, but its production is limited by weeds due to competition for abiotic factors, as well as producing allelopathic substances capable of interfering with the quality and productivity of the crop. The objective of this study was to evaluate the efficiency of the glyphosate herbicide, isolated or in combination with haloxyfop-p-methyl, in the control of bittergrass (Digitaria insularis). The work was developed in an experimental area with the soybean crop and spontaneous development of weeds. The treatments were: recommended dose of glyphosate $\left(720 \mathrm{~g} \mathrm{ha}^{-1}\right.$ e.a.); recommended dose of haloxyfop (60 $\mathrm{g} \mathrm{ha}^{-1}$ a.i.); half dose of glyphosate + half dose of haloxyfop (360 $\mathrm{g} \mathrm{ha}^{-1} \mathrm{e.a.}+30 \mathrm{~g}$ ha-1 a.i., respectively); recommended dose of glyphosate + haloxyfop; half dose of glyphosate + recommended dose of haloxyfop; recommended dose of glyphosate + half dose of haloxyfop; control without the presence of weeds. The productive components of soybean, phytotoxicity of the herbicide in the crop and the invasive species, and the plant mass of the weed were evaluated. The treatments with haloxyfop alone or in combination with glyphosate promote yellowing evolving towards amargoso necrosis; however, in application of glyphosate alone, this showed little or no effect on the weeds, indicating a possible tolerance of the biotype of the bitter grass to the glyphosate. Soybean yield decreased by up 3,059 $\mathrm{kg} \mathrm{ha}^{-1}(90.10 \%)$ when compared to areas where there was application. The population of soybean plants per linear meter is significantly reduced when there is no chemical control of weeds.
\end{abstract}

Keywords: Digitaria insularis; phytointoxication; herbicide.

\section{INTRODUÇÃO}

A soja (Glycine max L.), representa atualmente, um dos pilares do agronegócio brasileiro, se destacando como uma das principais culturas voltada a produção de grãos, com crescimento expressivo no quantitativo produzido. Este potencial alcançado pela cultura é resultado da grande capacidade de inserção no mercado internacional, principalmente devido o comércio de produtos do complexo agroindustrial da soja, além do uso dos grãos como fonte de proteína vegetal, que decorrente do aumento da demanda, possibilitou que a cultura se expandisse para diversas regiões (HIRAKURI; LAZZAROTTO, 2014). Entretanto, a 
ocorrência de plantas daninhas no local de cultivo resulta em perdas diretas a cultura principal, como a interferência por competição por umidade, nutrientes e luminosidade e por possuir substancias alelopáticas, que causam redução no rendimento, além de danos indiretos como a dificuldade na colheita, aumento de custo de produção e consequentemente, depreciação da qualidade do produto final provocando perdas de $15 \%$ na produção mundial de grãos (VASCONCELOS et al., 2012).

Diversos são os métodos que podem ser empregados no controle de plantas daninhas, dentre eles, o mais utilizado pelos agricultores é o manejo químico, em razão de sua rápida ação e eficiência de controle em diferentes épocas de aplicação, atingindo aproximadamente $22 \%$ das vendas de produtos químicos voltados a seu controle na cultura da soja.

Uma maneira de manejo preventivo na entressafra é a utilização de herbicidas de amplo espectro de ação, que atua no controle tanto de mono como dicotiledôneas. Estes herbicidas podem ser utilizados no mesmo período, em substituição ao manejo mecânico. Dentre os herbicidas disponíveis no mercado, o glyphosate, sulphosate, 2,4-D, paraquat, paraquat + diuron e flumioxazin, são os mais utilizados pelos produtores. O emprego de um ou mais produtos e diferentes doses, dependem das espécies presentes na área, do estágio fenológico e da cultura subsequente a ser implantada (CORREIA, 2002).

O uso de glyphosate é um importante método de controle de plantas daninhas no cultivo da soja RR (resistente ao glyphosate), devido ter ótimo resultado de controle sob biótipos tolerantes a outros tipos de herbicidas utilizados em cultivares de soja convencional. Porém, a tecnologia da soja $\mathrm{RR}$, faz parte de um programa tecnológico de manejo intensivo a resistência de certos ingredientes ativos de alguns tipos de herbicidas.

A disseminação do capim amargoso (Digitaria insularis) tem evoluído nas áreas de cultivo onde há ausência de culturas para cobertura estabelecidas na entressafra (BRIGHENTI, 2001). O capim amargoso ocorre comumente em pastagens, mas com o cultivo em semeadura direta, tornou-se uma das principais plantas daninhas no Brasil em áreas de produção de grãos (GAZZIERO et al., 2011).

A elaboração de herbicidas com novos mecanismos de ação, ainda é insuficiente, de forma que as medidas de controle devem ser trabalhadas com herbicidas atuais, com o método de misturas, época de aplicação, ou outras formas de manejo. Contudo, o manejo preventivo é a melhor opção, evitando o surgimento de biótipos tolerantes ao glyphosate. Como o glyphosate e o haloxifop são os mais usados como graminicidas em pós-emergência, o uso com herbicidas inibidores da ACCase para o manejo de Digitaria insularis tolerante ao glyphosate, vem sendo uma das medidas com maior eficiência a curto prazo (GEMELLI et al., 2013).

O objetivo deste estudo foi verificar a eficiência do herbicida glyphosate, isolado ou em mistura com haloxifopp-methyl (Verdict) no controle do capim amargoso (Digitaria insularis).

\section{MATERIAL E MÉTODOS}

O presente estudo foi desenvolvido no ano agrícola 2016/2017, entre outubro a fevereiro, no município de Terra Nova do Norte - MT, localizada à Latitude $10^{\circ} 31^{\prime} 6^{\prime \prime}$ Sul e
Longitude 55० $13^{\prime} 56^{\prime \prime}$ Oeste. Segundo a classificação de Köppen, o clima da região é do tipo Aw, clima tropical, característico por apresentar chuvas mais frequentes e intensas no verão, com temperatura média anual de $25,3{ }^{\circ} \mathrm{C}$ e pluviosidade de aproximadamente $2060 \mathrm{~mm}$, estando a uma altitude de 250 metros (ALVARES et al., 2014).

O solo da área experimental foi classificado como Latossolo Vermelho Amarelo Distrófico (EMBRAPA, 2013), apresentando as seguintes características: matéria orgânica: 23,44 $\mathrm{g} \mathrm{dm}^{-3}$; argila: $475 \mathrm{~g} \mathrm{dm}^{-3}$; silte: $217 \mathrm{~g} \mathrm{dm}^{-3}$; areia: $308 \mathrm{~g} \mathrm{dm}^{-3}$; $\mathrm{pH}$ em água: 4,8; P: 8,62 $\mathrm{mg} \mathrm{dm}^{-3}$; $\mathrm{K}: 6,3$ $\mathrm{cmol}_{\mathrm{c}} \mathrm{dm}^{-3}$; Ca: 2,01 $\mathrm{cmol}_{\mathrm{c}} \mathrm{dm}^{-3} ; \mathrm{Mg}: 0,81 \mathrm{cmol}_{\mathrm{c}} \mathrm{dm}^{-3}$; SB: 9,12 $\mathrm{cmol}_{\mathrm{c}} \mathrm{dm}^{-3}$; V: 39,27\% e CTC: 7,58 $\mathrm{cmol}_{\mathrm{c}} \mathrm{dm}^{-3}$.

O experimento foi realizado em área de produção de soja $\mathrm{RR}$ intacta (soja resistente a Round- $\mathrm{Up}^{\circledR}$, e ao ataque das lagartas Anticarsia gemmatalis, Chrysodeixis includens, Heliothis virescens e Epinotia aporema) cultivada no sistema de semeadura direta, cujo talhão contou com alta infestação por capim amargoso (Digitaria insularis) por toda a extensão da área. Durante todo o período de desenvolvimento da pesquisa, foram efetuados tratamentos fitossanitários e nutricionais comumente utilizados na propriedade rural, com restrição ao uso de herbicidas e roçagem, mantendo-se os procedimentos para o cultivo da soja.

O delineamento experimental utilizado foi inteiramente ao acaso, com 8 tratamentos e quatro repetições, totalizando 32 parcelas de $2,7 \mathrm{~m}$ de largura e $2,5 \mathrm{~m}$ de comprimento, atingindo $6,75 \mathrm{~m}^{2}$.

Os tratamentos constituíram-se de: dose cheia somente de glyphosate (Round-Up $\left.{ }^{\circledR}\right)$ (720 $\mathrm{g} \mathrm{ha}^{-1}$ e.a.); dose cheia somente com haloxyfop (Verdict $\left.{ }^{\mathbb{R}}\right)\left(60 \mathrm{~g} \mathrm{ha}^{-1}\right.$ i.a. $)$; meia dose de glyphosate (360 $\mathrm{g} \mathrm{ha}^{-1}$ e.a.) + meia dose de haloxyfop (30 $\mathrm{g}$ ha-1 i.a.) em mistura; dose cheia dos herbicidas glyphosate + haloxyfop em mistura (720 $\mathrm{g} \mathrm{ha}^{-1}$ e.a. $+60 \mathrm{~g} \mathrm{ha}^{-1}$ i.a.) respectivamente; meia dose de glyphosate ( $360 \mathrm{~g} \mathrm{ha}^{-1}$ e.a.) em mistura com dose cheia de haloxyfop (60 $\mathrm{g} \mathrm{ha}^{-1}$ i.a.); dose cheia de glyphosate (720 $\mathrm{g} \mathrm{ha}^{-1}$ e.a.) em mistura com meia dose de haloxyfop (30 $\mathrm{g} \mathrm{ha}^{-1}$ i.a.); testemunha sem a presença de plantas daninhas e testemunha com presença de daninhas.

Os tratamentos foram aplicados com o auxílio de pulverizador costal pressurizado a $\mathrm{CO}_{2}$, calibrado a 30 psi de pressão, e regulado para um volume de aplicação de $200 \mathrm{~L}$ $\mathrm{ha}^{-1}$. A barra de aplicação era equipada com 4 pontas de pulverização do tipo "leque" XR110.02 VS. A pulverização foi realizada aos 4 dias após a semeadura da cultura da soja, e quando as plantas de capim-amargoso apresentavam altura média de $30 \mathrm{~cm}$ e desenvolvimento reprodutivo pleno, considerando-se a distância do colo da planta até a extremidade da panícula.

Aos 14, 21, 29, 46 e 57 dias (03/12; 10/12; 18/12; 04/01/ e 15/01, respectivamente) após a aplicação (DAA) dos herbicidas foram realizadas as avaliações visuais de controle, utilizando- se como escala, notas de 0 a $100 \%$, onde zero representa a ausência de injurias visuais e 100 a morte das plantas. Aos $42 \mathrm{DAA}$, foram lançados quadros de $0,5 \mathrm{~m}^{2}$ de área interna, aleatoriamente na área útil das parcelas, coletando-se toda a parte aérea das plantas de capimamargoso.

Posteriormente, o material foi acondicionado em sacos de papel kraft, devidamente identificados e levados para estufa de circulação forçada de ar á $65^{\circ} \mathrm{C}$, até atingirem massa constante, para obtenção da massa seca. 
Aos 110 dias após a semeadura (DAS), realizou-se a dessecação da cultura, com a aplicação do dessecante paraquat na dose de 1,0 $\mathrm{L} \mathrm{ha}^{-1}$ (p.c.).

Ao atingir a maturação fisiológica (uma semana após a dessecação), foram coletadas 10 plantas aleatoriamente entre as linhas centrais de cada parcela para determinar os seguintes parâmetros: altura de plantas (medida entre o colo da planta e o ápice do caule); altura de inserção da primeira vagem; número de vagens e de grãos por planta; número de grãos por vagem, determinado dividindo-se o número médio de grãos pelo número médio de vagens por planta, sendo a colheita e debulha das vagens e grãos, realizadas manualmente, onde depois de limpos, foram acondicionados em sacos de papel e identificados.

Os resultados obtidos foram submetidos à análise de variância (teste F) e quando significativos, realizado o teste de Tukey a $5 \%$ de probabilidade, com auxílio do software estatístico R (R Development Core Team, 2018).

\section{RESULTADOS}

$\mathrm{Na}$ análise de variância (Tabela 1), foi detectado efeito significativo para as variáveis número de plantas de soja por metro linear (PM), altura de plantas (ALT), total de vagens por planta (NVP), peso de cem grãos (PCG), produtividade (PROD) e massa seca de capim amargoso (MSC). Para inserção da primeira vagem (INS) não houve efeito dos tratamentos.

Para o número de plantas por metro linear, a partir da aplicação dos herbicidas glyphosate e haloxyfop, assim como, com o emprego da capina manual, estas atingiram médias entre 12,1 e 14,0 plantas de soja (Tabela 1). No entanto, o tratamento onde as plantas de capim-amargoso não foram controladas, contabilizou-se em média 8,4 plantas por metro linear, ocasionando redução de $33 \%$ no número de plantas de soja por unidade de área, simplesmente pela ausência de controle da planta daninha.

Com relação à altura das plantas de soja em função da aplicação dos herbicidas para controle do capim-amargoso, as plantas com maiores estaturas estavam no tratamento em que não se realizou o controle das plantas daninhas, atingindo médias de 61,8 cm (Tabela 1). Nesse tratamento verificou-se uma grande quantidade de indivíduos de capim-amargoso por unidade de área, formando uma densa comunidade infestante.

Para a altura de inserção de primeira vagem, não foi observada diferença significativa entre os tratamentos químicos, controle manual e sem controle de capim amargoso na área estudada.

Quanto ao número de vagens por planta, foi verificado que no tratamento com a presença de plantas daninhas (sem controle), houve formação de menor número de vagens por plantas, atingindo média de apenas 2,4 vagens por plantas (Tabela 1).

Ao se comparar os demais tratamentos, verificou-se que a aplicação de glyphosate a $720 \mathrm{~g} \mathrm{ha}^{-1}$ e.a. não foi eficiente no controle da matocompetição, obtendo média de 7,53 vagens por planta. Os demais tratamentos constituídos por haloxyfop isolado ou a mistura deste com diferentes concentrações de glyphosate, alcançaram médias que variaram entre 10,22 e 13,93 vagens por planta.

Tabela 1. Diferença mínima significativa (DMS - Tukey 5\%), com valores de quadrado médio para número de plantas de soja por metro linear (PM), altura de plantas (ALT), inserção da primeira vagem (INS), total de vagens por planta (NVP), peso de cem grãos (PCG), produtividade (PROD) e massa seca de capim amargoso (MSC), submetidas à aplicação dos herbicidas glyphosate, haloxyfop e capina manual. Terra Nova do Norte - MT, 2018.

Table 1. Mean minimum difference (DMS - Tukey 5\%), with mean square values for number of soybean plants per linear meter (PM), plant height (ALT), first pod insertion (INS), total pods per plant (TVP), weight of one hundred grains (PCG), yield (PROD) and dry mass of bitter grass (MSC), submitted to herbicide glyphosate, haloxyfop and manual weeding. Terra Nova do Norte - MT, 2018.

\begin{tabular}{lccccccc}
\hline TRATAMENTO & PM & ALT & INS & NVP & PCG & PROD & MSC \\
\hline TSD & $8,4 \mathrm{~B}$ & $61,8 \mathrm{~A}$ & 17,2 & $2,4 \mathrm{C}$ & $15,0 \mathrm{DE}$ & $335,9 \mathrm{C}$ & $297,9 \mathrm{~A}$ \\
TCD & $12,1 \mathrm{~A}$ & $56,1 \mathrm{AB}$ & 17,6 & $13,9 \mathrm{~A}$ & $16,9 \mathrm{C}$ & $3267,2 \mathrm{~A}$ & $0,0 \mathrm{~B}$ \\
G75 & $14,0 \mathrm{~A}$ & $54,5 \mathrm{AB}$ & 17,7 & $7,5 \mathrm{~B}$ & $14,9 \mathrm{E}$ & $1851,3 \mathrm{~B}$ & $233,0 \mathrm{~A}$ \\
V20 & $13,2 \mathrm{~A}$ & $48,9 \mathrm{~B}$ & 16,5 & $10,2 \mathrm{AB}$ & $17,9 \mathrm{~B}$ & $2732,6 \mathrm{~A}$ & $20,3 \mathrm{~B}$ \\
G37+V10 & $13,6 \mathrm{~A}$ & $57,3 \mathrm{AB}$ & 18,5 & $12,7 \mathrm{~A}$ & $17,0 \mathrm{C}$ & $3394,2 \mathrm{~A}$ & $9,4 \mathrm{~B}$ \\
G37+V20 & $12,8 \mathrm{~A}$ & $51,3 \mathrm{AB}$ & 17,2 & $11,5 \mathrm{AB}$ & $17,6 \mathrm{BC}$ & $2754,3 \mathrm{~A}$ & $14,4 \mathrm{~B}$ \\
G75+V10 & $13,4 \mathrm{~A}$ & $54,5 \mathrm{AB}$ & 16,5 & $10,9 \mathrm{AB}$ & $15,9 \mathrm{D}$ & $3199,2 \mathrm{~A}$ & $5,9 \mathrm{~B}$ \\
G75+V20 & $13,1 \mathrm{~A}$ & $56,1 \mathrm{AB}$ & 15,1 & $12,2 \mathrm{AB}$ & $19,1 \mathrm{~A}$ & $3169,9 \mathrm{~A}$ & $5,5 \mathrm{~B}$ \\
\hline Valor de F & $12,648^{*}$ & $59,426^{*}$ & $4,179 \mathrm{~ns}$ & $54,098^{*}$ & $8,401 *$ & $4278043^{*}$ & $57617,1^{*}$ \\
DMS Tukey (5\%) & 2,5 & 12,2 & 6,0 & 5,1 & 0,88 & 764,2 & 132,7 \\
Média geral & 12,5 & 55,0 & 17,0 & 10,1 & 16,8 & 2588,1 & 73,3 \\
\hline CV (\%) & 8,67 & 9,38 & 15,01 & 21,13 & 2,21 & 12,45 & 76,29 \\
\hline
\end{tabular}

Médias seguidas da mesma letra na coluna $*$ Significativo a $5 \%$ de probabilidade pelo teste $\mathrm{F}$; ns não significativo

TSD: parcelas sem controle das plantas daninhas; TCD: parcelas com controle total das plantas daninhas através de capina manual; G75: aplicação de glyphosate a $720 \mathrm{~g} \mathrm{ha}^{-1}$ e.a.; V20: aplicação de haloxyfop a $60 \mathrm{~g} \mathrm{ha}^{-1}$ i.a.; G37+V10: aplicação de glyphosate a $360 \mathrm{~g}$ ha-1 e.a.+ haloxyfop a $30 \mathrm{~g}$ ha-1 i.a.; G37+V20: aplicação de glyphosate a $360 \mathrm{~g} \mathrm{ha}^{-1}$ e.a.+ haloxyfop a $60 \mathrm{~g} \mathrm{ha}^{-1}$ i.a.; G75+V10: aplicação de glyphosate a $720 \mathrm{~g}$ ha-1 e.a. + haloxyfop a $30 \mathrm{~g}$ ha ${ }^{-1}$ i.a.; G75+V20: aplicação de glyphosate a $720 \mathrm{~g} \mathrm{ha}^{-1}$ e.a. + haloxyfop a $60 \mathrm{~g} \mathrm{ha} \mathrm{h}^{-1}$ i.a.

Para produtividade da cultura da soja, todos os tratamentos em que foi usado o haloxyfop, isolado ou em mistura com glyphosate, atingiram valores entre 2732 e 3394 $\mathrm{kg}$ por hectare para esta variável (Tabela 1). O menor valor foi o tratamento em que não se interviu no desenvolvimento das plantas de capim-amargoso, obtendo apenas $335 \mathrm{~kg} \mathrm{ha}^{-1}$. Já a aplicação isolada de glyphosate também foi ineficiente para impedir a redução na produtividade da soja (1851 kg ha1), diferenciando-se dos demais tratamentos, mas ainda assim, superior ao tratamento sem controle das plantas daninhas. 
Em todos os tratamentos com controle químico nas cinco datas de avaliações, não foram observados sintomas de fitointoxicação nas plantas de soja (Figura 1), o que indica a resistência da cultivar transgênica ao herbicida inibidor da enzima 5-enolpiruvilshikimate-3-fosfato sintase (EPSPs). Entretanto, nas plantas de capim-amargoso, verificou-se amarelecimento, que foi evoluindo para necrose e morte das plantas quando estas foram submetidas a tratamento de glyphosate a $720 \mathrm{~g} \mathrm{ha}^{-1}$ e.a.+ haloxyfop a $30 \mathrm{~g} \mathrm{ha}^{-1}$ i.a. No tratamento apenas com glyphosate, o capim-amargoso não apresentou sintomas de fitotoxicidade.

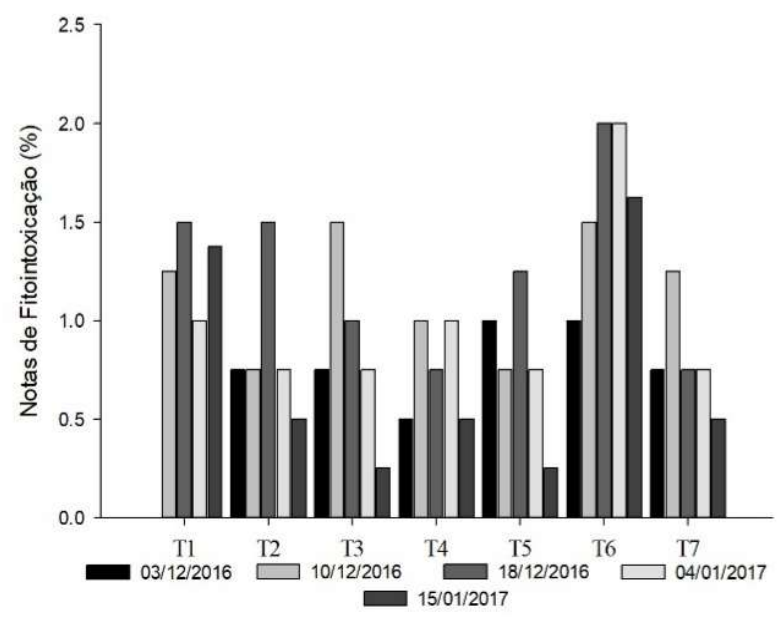

Figura 1. Fitointoxicação de plantas de soja submetidas a tratamento herbicida com glyphosate, haloxyfop e capina manual. Terra Nova do Norte-MT, 2018.

Figure 1. Phytotoxification of soybean plants submitted to herbicide treatment with glyphosate, haloxyfop and manual weeding. Terra Nova do Norte-MT, 2018.

$\mathrm{T} 1=\mathrm{TCD}$ : parcelas com controle total das plantas daninhas com capina manual; T2= G75: aplicação de glyphosate a $720 \mathrm{~g}_{\text {ha }}{ }^{-1}$ e.a.; T3= V20: aplicação de haloxyfop a $60 \mathrm{~g} \mathrm{ha}^{-1}$ i.a.; T4= G37+V10: aplicação de glyphosate a $360 \mathrm{~g} \mathrm{ha}^{-1}$ e.a. + haloxyfop a $30 \mathrm{~g} \mathrm{ha}^{-1}$ i.a.; T5= G37+V20 aplicação de glyphosate a $360 \mathrm{~g} \mathrm{ha}^{-1}$ e.a. + haloxyfop a $60 \mathrm{~g} \mathrm{ha}^{-1}$ i.a.; T6= G75+V10: aplicação de glyphosate a $720 \mathrm{~g} \mathrm{ha}^{-1}$ e.a.+ haloxyfop a $30 \mathrm{~g} \mathrm{ha}^{-1}$ i.a.; T7 $=\mathrm{G} 75+\mathrm{V} 20$ : aplicação de glyphosate a $720 \mathrm{~g} \mathrm{ha}^{-1}$ e.a. + haloxyfop a $60 \mathrm{~g} \mathrm{ha}^{-1}$ i.a.

Para a variável massa seca de plantas de capim-amargoso, o volume de massa seca observado apenas nas plantas onde não houve controle químico ou manual, e no tratamento com aplicação de glyphosate isoladamente (T2) com a $720 \mathrm{~g} \mathrm{ha}^{-1}$ e.a, indicam que o herbicida tem pouco ou nenhum efeito sobre a planta daninha (Tabela 1 e Figura 2).

No tratamento onde houve o controle das plantas daninhas por meio de capina manual, estas não apresentaram volume de massa seca. Com a aplicação dos herbicidas glyphosate e haloxyfop, as plantas de capim-amargoso demonstraram redução de massa seca. Entretanto, não houve diferença entre as doses de herbicidas utilizadas, com o demonstrado na Figura 2.

\section{DISCUSSÃO}

No período em que as plantas de capim-amargoso foram avaliadas, observou que as mesmas competiram com a cultura da soja pelos fatores abióticos, sendo suficiente para causar danos significativos no desenvolvimento da cultura, chegando haver perda de até $33 \%$, no número de plantas por metro linear (Tabela 1). De modo geral, plantas de soja apresentam habilidade competitiva bastante variável, sendo influenciada pelo espaçamento utilizado, densidade de semeadura, época e a extensão do período de convivência entre a cultura e as plantas daninhas (GEMELLI et al., 2012). A soja, por apresentar um período crítico de matocompetição entre 21 e 30 dias (Nepomuceno et al., 2007), sofreu efeito da presença do capim-amargoso, havendo redução em seu estabelecimento como verificado no presente estudo, onde observou-se que na presença do capim-amargoso, sua distribuição e densidade populacional foram fatores primordiais para suprimir as plantas da cultura.

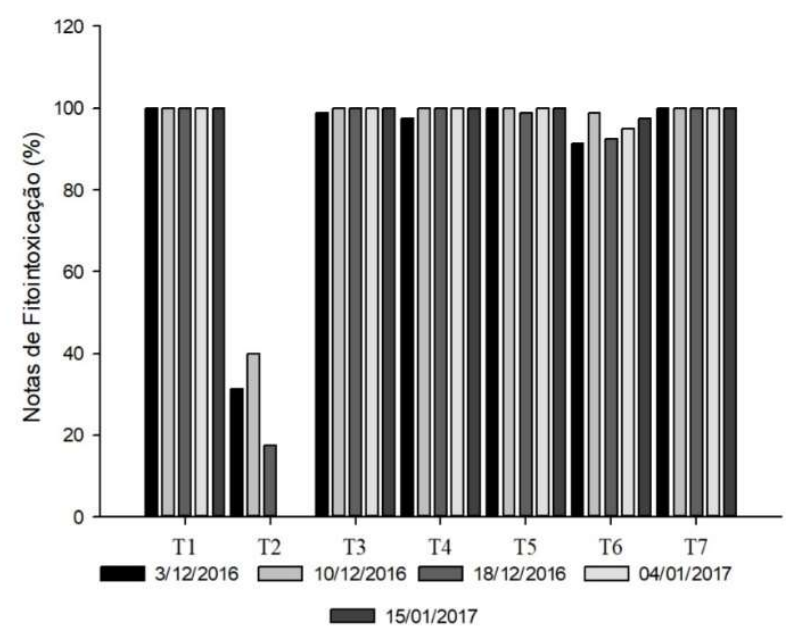

Figura 2. Notas de controle de plantas de capim amargoso submetidas a tratamento herbicida com glyphosate, haloxyfop e capina manual. Terra Nova do Norte-MT, 2018. Figure 2. Control notes of bitter grass plants submitted to herbicide treatment with glyphosate, haloxyfop and manual weeding. Terra Nova do Norte-MT, 2018.

$\mathrm{T} 1=\mathrm{TCD}:$ parcelas com controle total das plantas daninhas com capina manual; T2= G75: aplicação de glyphosate a $720 \mathrm{~g}^{2} \mathrm{a}^{-1}$ e.a.; T3= V20: aplicação de haloxyfop a $60 \mathrm{~g} \mathrm{ha}^{-1}$ i.a.; T4= G37+V10: aplicação de glyphosate a $360 \mathrm{~g} \mathrm{ha}^{-1}$ e.a. + haloxyfop a $30 \mathrm{~g} \mathrm{ha}^{-1}$ i.a.; T5= G37+V20: aplicação de glyphosate a $360 \mathrm{~g} \mathrm{ha}^{-1}$ e.a.+ haloxyfop a $60 \mathrm{~g} \mathrm{ha}^{-1}$ i.a.; T6= G75+V10: aplicação de glyphosate a $720 \mathrm{~g} \mathrm{ha}^{-1}$ e.a.+ haloxyfop a $30 \mathrm{~g} \mathrm{ha}^{-1}$ i.a.; $\mathrm{T} 7=\mathrm{G} 75+\mathrm{V} 20$ : aplicação de glyphosate a $720 \mathrm{~g} \mathrm{ha}^{-1}$ e.a.t haloxyfop a $60 \mathrm{~g} \mathrm{ha}^{-1}$ i.a.

A maior altura de plantas observadas no tratamento onde não houve emprego de manejo químico e manual, pode ser resultado da grande quantidade de indivíduos de capimamargoso na área, formando uma densa comunidade infestante e assim, causando interferência negativa neste parâmetro de desenvolvimento da cultura, provocando seu estiolamento. Assim como observado no presente estudo, Merotto et al. (2002), também verificaram plantas de maiores estaturas em condições de competição com plantas daninhas, provavelmente em virtude da diminuição da qualidade de luz recebida e absorvida, resultando na alteração de processos fisiológicos relacionados a dinâmica hormonal, além de reduzir a capacidade da planta em absorver nutrientes e água e de realizar fotossíntese (ALVINO et al., 2011).

De acordo com os resultados obtidos, houve dificuldade no controle químico das plantas daninhas, prejudicando o desenvolvimento da soja e causando redução na capacidade fotossintética destas, o que pode ter prejudicado todo o processo vegetativo da cultura da soja e, posteriormente 
refletindo no resultado reprodutivo, reduzindo a capacidade de desenvolvimento dos indicadores fitotécnicos, como o número de vagens por planta (Tabela 1). Os resultados observados no presente estudo demonstram que, mesmo com a aplicação do herbicida glyphosate (inibidor da EPSP's), esta prática não foi suficiente para o controle de plantas de capim-amargoso. Resultados semelhantes também têm sido verificados com a mesma espécie em diferentes regiões do Brasil (NICOLAI et al., 2010).

A ocorrência da resistência de capim-amargoso ao glyphosate tem se tornado um importante problema em diferentes regiões de sojicultura em todo o Brasil (CARVALHO et al., 2011). Os mecanismos bioquímicos que lhes confere resistência aos inibidores da 3-enolpiruvil shikimato fosfato sintase estão relacionados à capacidade dos biótipos resistentes em reduzir a velocidade de absorção do herbicida, e também à maior metabolização do glyphosate em aminometil fosfonato (AMPA), glioxilato e sarcosina (GEMELLI et al., 2013). Além disso, em biótipos resistentes, a translocação do herbicida é menor, se comparado aos biótipos susceptíveis, até mesmo quando as plantas são jovens (CARVALHO et al., 2011). Dessa maneira, a dificuldade no controle da planta daninha prejudicou o desenvolvimento da soja, afetando significativamente a produção de vagens.

De acordo com Radosevich (1997), quando ocorre aumento na densidade e posterior desenvolvimento das espécies infestantes, em especial aquelas que surgiram no início do ciclo da soja, há uma intensificação tanto da competição tanto intra como inter-específica. Assim, as plantas daninhas com maior porte tornam-se dominantes, e as menores são suprimidas ou morrem (NEPOMUCENO et al., 2007). Assim, o comportamento verificado em uma comunidade de plantas daninhas, pode justificar a redução na densidade das plantas com o aumento da matéria seca especialmente nos períodos de desenvolvimento finais da soja, afetando indicadores, como no caso do presente estudo, a massa dos grãos produzidos.

A cultura estudada teve sua produtividade significativamente reduzida devido a interferência do capimamargoso, mesmo quando o tratamento utilizou glyphosate, sendo portanto, este herbicida, nas condições do estudo, ineficaz para contenção do desenvolvimento da espécie daninha.

Diferenças na adaptabilidade de espécies tolerantes ou resistentes a herbicidas, como é o caso do capim-amargoso verificado no presente estudo, tem sido comumente usados para realização de comparações de capacidade produtiva de espécies de interesse agronômico, como a soja e, a principal variável indicativa do efeito negativo das plantas daninhas é a produtividade (WARWICK, 1994).

A dose recomendada de glyphosate para o controle do capim-amargoso, segundo Rodrigues e Almeida (2011) varia entre 720 e $1080 \mathrm{~g}$ e.a. ha ${ }^{-1}$, entretanto, mesmo utilizando (dose cheia com $720 \mathrm{~g}$ e.a. ha ${ }^{-1}$ ), a espécie não foi controlada eficientemente. De acordo com Melo (2015), caso a planta daninha tenha um desenvolvimento rápido, exigem-se aplicações com mais frequência e maiores doses. Entretanto, a prática mais adequada de manejo dessas espécies, com indicativo de resistência seria a alternância de mecanismos de ação, tanto para evitar a pressão de seleção de biótipos resistentes como para remediar uma possível seleção que já esteja ocorrendo (YAMASHITA, 2013). Essa diversificação de herbicidas poderia reduzir inclusive o banco de sementes da espécie daninha no solo (NOSWORTH et al., 2012).

A comprovação da ineficácia do glyphosate em controlar o capim-amargoso e o indicativo deste biótipo apresentar tolerância também foi constatada no acúmulo de massa seca da planta daninha ao final do experimento.

Para a fitointoxicação da cultura da soja, não foram observados sintomas nas plantas em tratamentos com herbicidas (Figura 1), indicando a resistência da cultivar transgênica ao herbicida inibidor da EPSP's. Entretanto, nas plantas de capim-amargoso, verificou-se amarelecimento, que foi evoluindo para necrose e morte das plantas quando estas foram submetidas a tratamento com a mistura de glyphosate e haloxyfop.

Ainda, segundo Melo (2015), a tolerância de biótipos de capim-amargoso pode ser advinda de dois diferentes tipos de EPSP's, representadas pela sensibilidade à molécula: a primeira classe (I) ocorre quando a atividade do herbicida é inibida por baixas concentrações do produto, sendo encontrada em todas as plantas e também em bactérias como Salmonella typhumurium e Escherichia coli (FRANZ et al., 1997). A outra classe (II) é a que permite a habilidade de manter a atividade catalítica mesmo na presença de elevadas concentrações de glyphosate, e é encontrada em algumas espécies de bactérias, Staphylococcus aureus e Agrobacterium sp. CP4 (DILL et al., 2008).

A capacidade de suportar o efeito do glyphosate com a enzima da Classe I pode ocorrer naturalmente (processo de seleção natural) ou ser obtida artificialmente. O glyphosate e o fosfoenolpiruvato (PEP) se ligam no mesmo local na EPSP's, portanto, espera-se que os indivíduos que possuem a mutação nessa condição tenham herdado tanto menor afinidade ao PEP como ao glyphosate (FRANZ et al., 1997).

\section{CONCLUSÕES}

Os tratamentos com haloxyfop isolado ou em mistura com glyphosate causam amarelecimento de até 100\% das plantas de capim amargoso, evoluindo para necrose, entretanto, em aplicação de glyphosate isoladamente, este não apresenta eficiência, indicando que o biótipo do capim amargoso pode ser resistente a glyphosate.

No tratamento sem controle químico, a produtividade da soja é influenciada diretamente pelas plantas daninhas, apresentando decréscimo de até $3.059 \mathrm{~kg} \mathrm{ha}^{-1}$ (90,10\%) quando comparado com áreas onde houve aplicação. Nos talhões onde as plantas daninhas não são submetidas ao controle químico, a população de plantas de soja por metro linear é reduzida significativamente.

\section{REFERÊNCIAS}

ALVARES C. A.; STAPE, J. L.; SENTELHAS, P. C.; GONÇALVES, J. L. M.; SPAROVEK, G. Koppen's climate classification map for Brazil. Meteorologische Zeitschrift, Berlin, v. 22, n. 6, p. 711-728, 2014. DOI: https://dx.doi.org/10.1127/0941-2948/2013/0507

ALVINO, C. A.; GRICIO, L. H.; SAMPAIO, F. A.; GIROTTO, M.; FELIPE, A. L. S.; JUNIOR, C. E. I.; BUENO, C. E. M. S.; BOSQUÊ, G. G.; LIMA, F. C. C. Efeito de espaçamentos e doses de nitrogênio sobre as características qualitativas da produção do repolho. Revista Científica Eletrônica de Agronomia, Brasília, v. 23, n. 1, p. 266-270, 2011. DOI: http:/ /dx.doi.org/10.1590/S0102-05362005000100021 
BRIGHENTI, A. M.; Biologia de plantas daninhas. In: OLIVEIRA JÚNIOR, R. S.; CONSTANTIN, J. (Eds). Plantas daninhas e seu manejo. Guaíba: Agropecuária, 2001. p. 18-58.

CARVALHO, L. B.; CRUZ-HIPOLITO, H.; GONZÁLEZ-TORRALVA，F.; ALVES, P. L. D.; CHRISTOFFOLETI, P. J.; DE PRADO, R. Detection of sourgrass (Digitaria insularis) biotypes resistant to glyphosate in Brazil. Weed Science, Champaign, v. 59, n. 2, p. 171-176, 2011. DOI: https://dx.doi.org/10.1614/WS-D-10-00113.1

CORREIA, N. M.; REZENDE, P. M. Manejo integrado de plantas daninhas na cultura da soja. Lavras: Editora UFLA, 2002. 55 p.

DILL, G. M.; JACOB, C. A.; PADGETTE, S. R. Glyphosate-resistant crops: adoption, use and future considerations. Pest Management Science, v. 54, n. 4, p. 326-331, 2008.2 DOI: https://dx.doi.org/10.1002/ps.1501

EMBRAPA_EMPRESA BRASILEIRA DE PESQUISA AGROPECUÁRIA. Sistema Brasileiro de Classificação de Solos. 3. ed. Brasília, Embrapa, 2013. $353 \mathrm{p}$.

FRANZ, J. E.; MAO, M. K.; SIKORSKI, J. A. Glyphosate: a unique global herbicide. 1. ed. American Chemical Society, 1997. 678 p.

GAZZIERO, D. P.; VOLL, E.; ADEGAS, F. S. Resistência de plantas daninhas aos herbicidas: situação atual e manejo. In: SIQUERI, F.; CAJU, J.; MOREIRA, M. Boletim de pesquisa de soja 2011. Rondonópolis: Fundação MT, 2011. p. 416-421. (Boletim de pesquisa da soja, 15).

GEMELLI, A.; OLIVEIRA JR, R. S.; CONSTANTIN, J.; BRAZ, G. B. P.; CAMPOS, J. T. M.; OLIVEIRA, A. M.; BIFFE, D. F. Aspectos da biologia de Digitaria insularis resistente ao glyphosate e implicações para o seu controle. Revista Brasileira de Herbicidas, Londrina, v. 11, n. 2, p. 231-240, 2012.2 DOI: https://dx.doi.org/10.7824/rbh.v11i2.186

GEMELLI, A.; OLIVEIRA JR., R. S.; CONSTANTIN, J.; BRAZ, G. B. P.; JUMES, T. M. C.; GHENO, E. A.; RIOS, F. A.; FRANCHINI, L. H. M. Estratégias para o controle de capim-amargoso (Digitaria insularis) resistente ao glyphosate na cultura milho safrinha. Revista Brasileira de Herbicidas, Londrina, v. 12, n. 2, p. 162 170, 2013.2 DOI: https://dx.doi.org/10.7824/rbh.v12i2.201

HIRAKURI, M. H.; LAZZAROTTO, J. J. O agronegócio da soja nos contextos mundial e brasileiro. Londrina: Embrapa Soja, 2014. 37 p. (Documentos, 349).
MELO, M. S. C. Levantamento de ocorrência, alternativas de manejo, mecanismos de resistência $\mathrm{e}$ herança genética do capim-amargoso (Digitaria insularis) resistente ao herbicida glyphosate. 2015. 108f. Tese (Doutorado em Ciências) - Escola Superior de Agricultura "Luiz de Queiroz", Piracicaba, 2015.

MEROT'TO, A.; VIDAL, R. A.; FLECK, N. G.; ALMEIDA, M. L. Interferência das plantas daninhas sobre $O$ desenvolvimento inicial de plantas de soja e arroz através da qualidade da luz. Planta Daninha, Viçosa, v. 20, n. 1, p. 9-16, 2002. DOI: http://dx.doi.org/10.1590/S010083582002000100002

NEPOMUCENO, M.; ALVES, P. L. C. A.; DIAS, T. C. S.; PAVANI, M. C. M. D. Períodos de interferência das plantas daninhas na cultura da soja nos sistemas de semeadura direta e convencional. Planta Daninha, Viçosa, v. 3, n. 1, p. 43-50, 2007. DOI: http://dx.doi.org/10.1590/S0100-83582007000100005

NICOLAI, M.; MELO, M. S. C.; LÓPEZ-OVEJERO, R. F.; CHRISTOFFOLETI, P. J. Monitoramento de infestações de populações de capim-amargoso (Digitaria insularis) suspeitas de resistência ao glifosato. In.: CONGRESSO BRASILEIRO DA CIENCIA DAS PLANTAS DANINHAS, 27., Ribeirão Preto, 2010. Anais... SBCPD: Ribeirão Preto, 2010. p. 943-946.

NOSWORTH, J. K.; WARD, S. M.; SHAW, D. R.; LEWELLYN, R. S. Reducing the risks of herbicide resistance: best management practices and recommendations. Weed Science, Champaign, v. 60, n.1, p. 31-62, 2012.

R Development Core Team. R: A language and environment for statistical computing. Viena: R Foundation for Statistical Computing; 2018. Disponível em: <https://www.R-project.org>. Acesso em: 02/10/2018.

RADOSEVICH, S. R.; HOLT, J. S.; GHERSA, C. Ecologia de ervas daninhas: implicações para o manejo. John Wiley \& Sons, 1997. 367 p.

RODRIGUES, B. N.; ALMEIDA, F. S. (Ed.). Guia de herbicidas. 6. ed. Londrina, PR: Edição dos autores, 2011. 697 p.

WARWICK, S.; BLACK, I. L. D. Relative fitness of herbicide resistant and susceptible biotypes of weeds. Phytoprotection, v. 75 , n. 4, p. 37-49, 1994. DOI: https://dx.doi.org/10.7202/706070ar

YAMASHITA, O. M.; GUIMARÃES, S. C. Resistência de plantas daninhas ao herbicida glyphosate. Varia Scientia Agrária, Cascavel, v. 3, n. 1, p. 189-215, 2013. 